\title{
Determination of Optimum Sample Size for Lot Acceptance Attribute Sampling under Life Tests Based On Rayleigh Distribution Using Graphical Evaluation Review Technique (GERT)
}

\author{
P. Kumarasamy ${ }^{1 *}$, S. Nagarathinam ${ }^{1}$, T. Asif ${ }^{1}$ \\ 1. Department of Statistics Bharathiar University, India
}

\begin{abstract}
This paper presents the graphical evaluation and review technique (GERT) exploration of performance measures for lot acceptance sampling procedures having attribute characteristics following life tests based on percentiles of Rayleigh Distribution and henceforth determining optimum sampling size. The advantageous implications of GERT analysis in this framework is primarily to visualize the dynamics of the sampling inspection system and secondly, critical analysis of sampling procedure characteristics. The formula of operating characteristics (OC) function and average sample number (ASN) function is derived and illustrated numerically. Lastly, tables have been provided to determine the optimum sample size assuring certain mean life or quality of the product.
\end{abstract}

Keywords: Reliability life test sampling plan, Graphical Evaluation Review Technique (GERT), Rayleigh Distribution.

\section{Introduction}

Acceptance model schemes are commonly used to determine product acceptance. Lifetime is an important quality attribute of an object. The prototypes used to determine the acceptability of a product for its lifetime are called reliability or life test prototype. When the life test shows that the mean (average) or percentage life of the product is above the desired quality, the submitted lot is accepted; otherwise it is rejected lot.

Reliability sampling is a process that establishes the minimum sample size to be used for testing. This is especially valuable if the quality of an object is defined in its lifetime. A specific reliability model project, in which case, sample observation is subject to the lifetime testing of the products, is intended to demonstrate that the actual population average exceeds the required minimum. Population mean refers to the average lifetime of a product, say $\theta$. If $\theta_{0}$ is a certain minimum value, one wants to check $\theta \geq \theta_{0}$; Lots rejected or life test model plan.

The decision-making criterion is naturally based on the number of failures observed in the sample of $n$

\footnotetext{
* Corresponding Author Email: pradeepaveerakumari@buc.edu.in
}

products in a given time $\mathrm{T}$ form, which is obtained at the lowest average lifetime unknown. If the number of failures found is large, greater than one number $c$, the lower limit obtained is smaller than $\theta_{0}$, and the hypothesis $\theta \geq \theta_{0}$ is not verified. So, a lot is unacceptable. Such a model plan is called a reliability model plan, an important feature of the reliability accepting model scheme is that it involves a randomness. The lifetime distribution can be adequately described by the consecutive type distributions such as Normal, Exponential, Weibull, Lognormal and Gamma. Many works have been done in previous years on the reliability model project using this distribution. In recent years, there have been a few other types of literature available, such as Logistics, Log-Logistics, Rayleigh, inverse Rayleigh, Generalized Exponential, Pareto, Marshall-Olk in Extended Lomax, Exponentiated Rayleigh, and, Exponentiated Exponential Distribution.

\section{Reliability Functions}

Basic to the definition of reliability functions and other related functions is the length of the variable. The length of life (lifetime) of a component/system is the length of the time interval $T$, from the initial activation of the unit 
until failure. This variable $T$ is considered a random variable, since the length of life cannot be exactly predicted.

The cumulative (life) distribution function (CDF) of $T$, denoted by $F(t)$ is the probability that the lifetime does not exceed t.

i.e.,

$$
F(t)=\operatorname{Pr}\{T \leq t\}, \quad 0<t<\infty
$$

The lifetime random variable $T$ is called continuous if its CDF is a continuous function of $t$. The probability density function (PDF) corresponding to $F(t)$ is its derivative (if it exists). We denote the PDF by $f(t)$. This is a non-negative valued function such that

$$
F(t)=\int_{0}^{t} f(x) d x, \quad 0<t<\infty
$$

The reliability function $R(t)$ of a component/system having a life distribution $F(t)$ is

$$
R(t)=1-F(t)=\operatorname{Pr}\{T>t\}
$$

This is the probability that the lifetime of the component/system will exceed $t$.another important function related to the life distribution is the failure rate or hazard function $h(t)$.this is the instantaneous failure rate of an element which has survived $t$ units of time. i.e.,

$$
h(t)=\lim _{\Delta \rightarrow 0} \frac{F(t+\Delta)-F(t)}{\Delta \operatorname{Pr}\{T>t\}}=\frac{f(t)}{R(t)}
$$

Notice that $h(t) \Delta t$ is approximately, for small $\Delta t$, the probability that a unit still functioning at age $t$ will fail during the interval $(t, t+\Delta t)$.

$$
\begin{aligned}
& \qquad h(t)=-\frac{d}{d t} \ln R(t), \\
& \text { and } \\
& \qquad R(t)=\exp \left\{-\int_{0}^{t} h(x) d x\right\} .
\end{aligned}
$$

\section{Mean Time to Failure (MTTF)}

The average length of time until failure (the expected value of $\mathrm{T}$ ). The general definition of the expected value of a lifetime random variable $T$ is

$$
E\{T\}=\int_{0}^{\infty} t f(t) d t,
$$

Provided this integral is finite. It can be shown that

$$
E\{T\}=\int_{0}^{\infty} R(t) d t
$$

The mean time to failure is denoted by MTTF and also it will simply called as $\mu$.

\section{Censoring}

Censoring is a major issue, especially in survival analysis. Censoring distinguishes survival analysis from conventional statistical problems. Censoring is done when an observation is incomplete for some random reasons. The reason for censorship usually depends on the occurrence of interest.
Censoring differs from Censoring in that the incompleteness of the observations for reduction occurs due to a systematic selection process inherent in the study design. There are five types of Censoring, based on the directions in which the incompleteness in the observations comes from

1) Type I Censoring

2) Type II Censoring

3) Random Censoring

4) Progressively censoring:

5) Hybrid censoring

Type I Censoring: Sometimes tests are performed within a certain period of time. Three the exact life span of an object is known only if it is less than some predetermined value. In that case, data are said to be type I censored (from right). More precisely a type I censored sample is one that arises when $n$ items numbered say $1,2 \ldots$, nare subject to limited periods of observations, and let $L_{1}, \ldots, L_{n}$ be those periods $\exists . i$ th item's lifetime $L_{i}$ is observable only if $T_{i} \leq L_{i}$. $L_{i}$ : called fixed censoring time for $i^{\text {th }}$ item If all $L_{i}$ are equal, data are said to be single type I censored.

Type II censoring: Suppose $n$ random sample units are set on life-testing experimentation. But due to some reasons the experiment terminates after smallest $r$ readings. Let these be denoted by the order statistics $T_{(1)} \ldots, T_{(r)}$. Here integer $r$ is prefixed i.e. nonrandom. Since the remaining $n-r$ random sample value are at least as high as high as $T_{(r)}$ : the sampling scheme is a censored one. Such a censoring is known as Type II censoring. Type II censoring are frequently used in life- testing experiments. Here say total of $n$ items are placed on test.

Right censoring: The general form of censoring here is the lifetime of an object until the event (i.e. failure or death) has not yet occurred, but after that time this event will not participate in the further study.

Left censoring: This occurs when the event of interest has already occurred at the time observed, but the exact time at which the event occurred is unknown.

Progressively censoring: A sample of randomly selected $\mathrm{n}$ units is placed in a life test. In the event of a failure, $r_{1}$ the units are approximately removed from the remaining $n_{1}$ units. At the time of the second failure $r_{2}$ units are approximately removed from the remaining $n-2-r_{1}$ units during the second failure. At any time the test continues until $m^{\text {th }}$ fails, all remaining $r_{m}=$ $n-m-r_{1}-r_{2}-\cdots-r_{m-1}$ units are removed.

Hybrid censoring: Combination of Type I and Type II censoringschemes. The sample life of approximately selected $\mathrm{n}$ units is subjected to testing. If a fixed number $r$ of $n$ items fails or the pre-determined time reaches $t$ during the test, the test will be stopped. 


\section{Life Distribution models and their characteristics}

\section{Types of Failure Observations}

A typical test of equipment life testing involves installing a sample of $n$ identical units on the appropriate equipment and subjecting the units to operating under specific conditions until the failure of equipment is detected. In this case, we have accurate information about the lifespan or failure time $T$ of that unit. The observed random variable, $T$ is a continuous variable, i.e. it can take any value at a given time interval. The second type of data arises when units are observed only at separate time pointst $t_{1}, t_{2}, \ldots \mathrm{N}$ The number of failures in the tested units is recorded for each of inter-inspection time interval. Let $N_{1}, N_{2}, \ldots$, Indicate the number of failed units at time intervals $\left[0, t_{1}\right),\left[t_{1}, t_{2}\right) \ldots$.these are unique random variables for the number of failures.

Proper analysis of the data depends on the observations available. Tests must often be stopped before all units of the test have failed. In such cases, we only have complete information about the time until failure (if monitoring is continuous) in a part of the model. We have only partial information on all failed units. Such data is called time censoring. If all the units start operating at the same time, we say that the censoring is single. Also known as one-time censoring type-I censoring. Some tests end in the event of $r$-th failure, where $r$ is smaller than the predetermined integer $\mathrm{n}$. In these cases the data is failed-censoring. The single failure censoring is called Type-II censoring. If different units start operating at different time points at intervals of $\left[o, t^{*}\right]$, and the test is stopped at $t^{*}$, . we have multiple data censoring. We are different from censoring on the left and censoring on the right. If some units start operating before the official time, we have censoring. The other type of censoring information that the unit is still in operation at the end of the monitoring is called proper censoring.

\section{General Characteristics of Life Distributions}

We consider here the continuous random variable, $\mathrm{T}$, which denotes the length of lie, or the length of time failure, in a continuous operation of the equipment. We denote by $F(t)$ the cumulative distribution function (CDF) of $\mathrm{T}$,

i.e.,

$$
F(t)=\operatorname{Pr}\{T \leq t\} .
$$

Obviously, $F(t)=0$ for all $t \leq 0$.We assume here that initially the equipment is in proper operating condition. Thus, we eliminate from consideration here defective or inoperative units. The CDF $F(t)$ is assumed to be continuous, satisfying the conditions.

1) $F(0)=0$;

2) $\lim _{t \rightarrow \infty} F(t)=1$;

3) If $t_{1}<t_{2}$ then $F\left(t_{2}\right) \leq F\left(t_{2}\right)$
The reliability at time $t$ is the probability that the life length of the equipment exceeds $t$ [time units]. The survival function is the same as the reliability function.

The probability density function (PDF) of a random variable, $T$, having a $\operatorname{CDF} F(t)$, is a non-negative function, $f(t)$, such that

$$
F(t)=\int_{0}^{t} f(t) d x, \quad 0 \leq t<\infty
$$

According to this definition, $f(t)$ can be determined, at almost all points of $t$, as the derivative of $F(t)$.

The $p^{t h}$ percentile point of a life distribution $F(t)$, for a value of $p$ in $(0,1)$, is the value of $t$, denoted by $t_{p}$, for which $F(t)=p$; i.e.,

$$
F\left(t_{p}\right)=p
$$

If there is more than one value of $t$ satisfying the above equation, we define $t_{p}$ to be the smallest one.The median, $t_{.50}$, and the lower and upper quartiles, $t_{.25}$ and $t_{.75}$, respectively, are important characteristics of a life distribution.

Moments of order $r$ of the life distribution are defined as

$$
\mu_{r}=\int_{0}^{\infty} t^{r} f(t) d t, \quad r=1,2, \ldots \ldots
$$

Moments $\mu_{r}$ may not be finite.

If the PDF, $f(t)$, is symmetric around a point $\bar{t}$, then $\mu=\bar{t}$ (provided $\mu$ is finite). Moreover, if $f(t)$ is symmetric then the median is equal to the MTTF.

Another important relationship is that

$$
\mu=\int_{0}^{\infty} R(t) d t
$$

Where $R(t)$ is the reliability function.

The failure rate function, associated with a life distribution $F(t)$, is

$$
h(t)=\frac{f(t)}{R(t)}, \quad 0 \leq t<\infty .
$$

The function $H(t)=\int_{0}^{t} h(x) d x$ is called the cumulative hazard function.

\section{References}

[1] Abubakar M.I and Singh,V.V. (2019). Performance assessment of African textile manufacturers, LTD, in Kano state, Nigeria, through Multi failure and repair using copula. Oper Res Decis 29(4):1-18

[2] Anand, J and Malik, S.C. 2012. Analysis of a Computer System with Arbitrary Distributions for $\mathrm{H} / \mathrm{W}$ and S/W Replacement Time and Priority to Repair Activities of $\mathrm{H} / \mathrm{W}$ over Replacement of the S/W, International Journal of Systems Assurance Engineering and Management, Vol.3 (3), pp. 230-236.

[3] Ashok Kumar, D. Pawar1 \& S. C. Malik. (2020). Reliability Analysis of a Redundant System with 'FCFS' 
Repair Policy Subject to Weather Conditions, International Journal of Advanced Science and Technology, 29(3),,7568 $-7578$

[4] Bisht, S and Singh, S. B. (2019), Reliability analysis od acyclic transmission network based on minimal cuts using copula in repair, Proceedings of the Jangjeon Mathematical Society,22(2019), No. 1, pp. 163-173.

[5] Kumar, A. and Malik, S. C. 2012. Stochastic Modeling of a Computer System with Priority to PM over S/W the Replacement Subject to Maximum Operation and Repair Times. International Journal of Computer Applications, Vol.43 (3), pp. 27-34.

[6] Kumar, Ashish; Anand, Jyoti and Malik, S.C. 2013. Stochastic Modeling of a Computer System with Priority to Up-gradation of Software over Hardware Repair Activities. International Journal of Agricultural and Statistical Sciences, Vol. 9(1), pp. 117-126.

[7] Kumar, A. \& Malik, S.C. 2014. Reliability modelling of a computer system with priority to $\mathrm{H} / \mathrm{w}$ repair over replacement of $\mathrm{H} / \mathrm{w}$ and up-gradation of $\mathrm{S} / \mathrm{w}$ subject to MOT and MRT, Jordan Journal of Mechanical and Industrial Engineering, Vol.8 (4), pp. 233-241.

[8] Kumar, A., Saini, M. and Malik, S.C. 2015. Performance Analysis of a Computer System with Fault Detection of Hardware, Procedia computer science,45, 602-610.

[9] Lado, A.K., Singh, V.V., Ismail K.H and Ibrahim, Y. (2018). Performance and cost assessment of repairable complex system with two subsystems connected in the series configuration. Int J Reliabil Appl 19(1):27-42

[10] Lado, A. and Singh, V. (2019), "Cost assessment of complex the repairable system consisting two subsystems in the series configuration using Gumbel Hougaard family copula", International Journal of Quality \& Reliability Management, Vol. 36 No. 10, pp. 1683-1698. https://doi.org/10.1108/IJQRM-12-2018-0322

[11] Liu, Y and Peng, Y.(2016). The application of computer network and research under the new media environment, evaluation of the computer network technology application tutorial (fourth edition). J Youth Press; 32:104-104. 10.1007/s11263011-0495-210.1049/iet-cta.2013.0676

[12] Malik, S. C. and Anand, J.2010. Reliability and Economic Analysis of a Computer System with Independent Hardware and Software Failures, Bulletin of Pure and Applied Sciences,Vol.29 E (Math. \& Stat.), No. 1, pp.141-153.

[13] Malik, S.C. and Sureria, J.K. 2012. Profit Analysis of a Computer System with H/W Repair and S/W Replacement. International Journal of Computer Applications, Vol.47(1), pp.19-26.

[14] Malik, S.C. 2013. Reliability Modelling of a computer System with Preventive Maintenance and Priority Subject to Maximum Operation and Repair Times. International Journal of System Assurance Engineering and Management, Vol. 4 (1), pp. 94-100.

[15] Malik, S.C. and Munday, V.J. 2014. Stochastic Modeling of a Computer System with Hardware Redundancy,
International Journal of Computer Applications, Vol. 89 (7), pp. 26-30.

[16] Niwas, R. and Garg, H. (2018), "An approach for analyzing the reliability and profit of an industrial system based on the cost-free warranty policy", Journal of the Brazilian Society of Mechanics and Engineering, Vol. 40 No. 5, pp. 1-9.

[17] Singh, V.V., Poonia, P.K and Abdullahi, A.H. (2020). Performance analysis of a complex repairable system with two subsystems in series configuration with imperfect switch, Journal of Mathematical and Computational Science, 10(2). 359-383

[18] Singh, V.V and Poonia, P. K.. (2019). Probabilistic Assessment of Two-Unit Parallel System with Correlated Lifetime under Inspection Using Regenerative Point Technique, IJRRS,2(1),5-14

[19] Temraz, N.S.Y.(2019). Availability and reliability of a parallel system under imperfect repair and replacement: analysis and cost optimization. Int J Syst Assur Eng Manag10, 1002-1009 https://doi.org/10.1007/s13198-019-00829-2

[20] Wang, K,-H and Kuo, C,-C. 2000. Cost and probabilistic analysis of series systems with mixed standby components, Applied Mathematical Modelling, 24: 957967.

[21] Wang,K., Hsieh, C and Liou, C. 2006. Cost benefit analysis of series systems with cold standby components and a repairable service station. Journal of quality technology and quantitative management, 3(1): 77-92.

[22] Yang, D. Y and Tsao, C. L. (2019). Reliability and availability analysis of standby systems with working vacations and retrial of failed components. Reliability Engineering \& System Safety, 182, 46-55.

[23] Yen, T, -C and Wang, K, -H. (2018). Cost-benefit analysis of three systems with imperfect coverage and standby switching failures, IJMOR, 12(2),253-272.DOI: 10.1504/IJMOR.2018.089680

[24] Yang, S.(2019)Analysis for the reliability of the computer network by using intelligent cloud computing method,International Journal of Computers and Applications,41:4,306-311,DOI: 10.1080/1206212X.2017.1417770

[25] Yusuf, I., Yusuf, B., Babagana, M., Sani, B and Lawan, M.A. (2018). Some reliability characteristics of a linear consecutive 2-out-of-4system connected to a 2-out-of-4 supporting device for operation. Int $\mathrm{J}$ Eng Technol 7(1):135-139.

[26] Yusuf I, Yufus B, Suleiman K (2019) Reliability assessment of a repairable system under online and offline preventive maintenance. Life Cycle Reliability Saf Eng 8(4):391-406.

[27] Zhao, B., Xie, L., Li, H., Zhang, S., Wang, B., and Li, C. (2020). Reliability analysis of aero-engine compressor rotor system considering cruise characteristics. IEEE Trans Reliab 68(4):245-259

[28] Zhang, F. (2019). Research on reliability analysis of computer network based on intelligent cloud computing method, International Journal of Computers and Applications, $\quad 41: 4, \quad 283-288, \quad$ DOI: 10.1080/1206212X.2017.1402622. 


\section{Appendix}

$M=\left(\begin{array}{cccccc}-\left(2 \beta_{0}+2 \beta_{1}\right) & 2 \beta_{0} & 2 \beta_{1} & 0 & 0 & 0 \\ \alpha_{0} & -\left(\alpha_{0}+\beta_{0}+2 \beta\right) & 0 & 2 \beta_{1} & 0 & 0 \\ \alpha_{1} & 0 & -\left(\alpha_{1}+2 \beta_{0}+2 \beta_{1}\right) & 2 \beta_{0} & 2 \beta & 0 \\ 0 & \alpha_{1} & \alpha_{0} & -\left(\beta_{0}+2 \beta_{1}+\alpha_{0}+\alpha_{1}\right) & 0 & 2 \beta_{1} \\ 0 & 0 & \alpha_{1} & 0 & -\left(\alpha_{1}+2 \beta_{0}+\beta_{1}\right) & 2 \beta_{0} \\ 0 & 0 & 0 & \alpha_{1} & \alpha_{0} & -\left(\beta_{0}+\beta_{1}+\alpha_{0}+\alpha_{1}\right)\end{array}\right)$

Table 1.States of the system

\begin{tabular}{|l|l|l|l|l|l|l|}
\hline \multicolumn{1}{|c|}{ State } & \multicolumn{1}{|c|}{ Client 1} & \multicolumn{1}{|c|}{ Client 2 } & \multicolumn{1}{c|}{ Client 3 } & \multicolumn{1}{c|}{ Server 1 } & \multicolumn{1}{c|}{ Server 2 } & \multicolumn{1}{c|}{ System's Status } \\
\hline $\mathrm{S}_{0}$ & Functional & Functional & Functional & Functional & Replication & Operative \\
\hline $\mathrm{S}_{1}$ & Functional & Functional & Functional & Failed & Functional & Operative \\
\hline $\mathrm{S}_{2}$ & Failed & Functional & Functional & Functional & Replication & Operative \\
\hline $\mathrm{S}_{3}$ & Failed & Functional & Functional & Failed & Functional & Operative \\
\hline $\mathrm{S}_{4}$ & Failed & Failed & Functional & Functional & Replication & Operative \\
\hline $\mathrm{S}_{5}$ & Failed & Failed & Functional & Failed & Functional & Operative \\
\hline $\mathrm{S}_{6}$ & Failed & Failed & Failed & Idle & Idle & Down \\
\hline $\mathrm{S}_{7}$ & Failed & Failed & Failed & Failed & Idle & Down \\
\hline $\mathrm{S}_{8}$ & Idle & Idle & Idle & Failed & Failed & Down \\
\hline $\mathrm{S}_{9}$ & Failed & Idle & Idle & Failed & Failed & Down \\
\hline $\mathrm{S}_{10}$ & Failed & Failed & Idle & Failed & Failed & Down \\
\hline
\end{tabular}

Table 2. Transition Table

\begin{tabular}{|c|c|c|c|c|c|c|c|c|c|c|c|}
\hline & $S_{0}$ & $S_{1}$ & $S_{2}$ & $S_{3}$ & $S_{4}$ & $S_{5}$ & $S_{6}$ & $S_{7}$ & $S_{8}$ & $S_{9}$ & $S_{10}$ \\
\hline$S_{0}$ & - & $3 \beta_{0}$ & $2 \beta_{1}$ & 0 & 0 & 0 & 0 & 0 & 0 & 0 & 0 \\
\hline$S_{1}$ & $\alpha_{0}$ & - & 0 & $2 \beta_{1}$ & 0 & 0 & 0 & 0 & $\beta_{0}$ & 0 & 0 \\
\hline$S_{2}$ & $\alpha_{1}$ & 0 & - & $2 \beta_{0}$ & $2 \beta_{1}$ & 0 & 0 & 0 & 0 & 0 & 0 \\
\hline$S_{3}$ & 0 & $\alpha_{1}$ & $\alpha_{0}$ & - & 0 & $2 \beta_{1}$ & 0 & 0 & 0 & $\beta_{0}$ & 0 \\
\hline$S_{4}$ & 0 & 0 & $\alpha_{1}$ & 0 & - & $2 \beta_{0}$ & $\beta_{1}$ & 0 & 0 & 0 & 0 \\
\hline$S_{5}$ & 0 & 0 & 0 & $\alpha_{1}$ & $\alpha_{0}$ & - & 0 & $\beta_{1}$ & 0 & 0 & $\beta_{0}$ \\
\hline$S_{6}$ & 0 & 0 & 0 & 0 & $\alpha_{1}$ & 0 & - & 0 & 0 & 0 & 0 \\
\hline$S_{7}$ & 0 & 0 & 0 & 0 & 0 & $\alpha_{1}$ & 0 & - & 0 & 0 & 0 \\
\hline$S_{8}$ & 0 & $\alpha_{0}$ & 0 & 0 & 0 & 0 & 0 & 0 & - & 0 & 0 \\
\hline$S_{9}$ & 0 & 0 & 0 & $\alpha_{0}$ & 0 & 0 & 0 & 0 & 0 & - & 0 \\
\hline$S_{10}$ & 0 & 0 & 0 & 0 & 0 & $\alpha_{0}$ & 0 & 0 & 0 & 0 & - \\
\hline
\end{tabular}


Table 3. Variation of availability, profit and MTTF with $\alpha_{1}$ and $\beta_{1}$

\begin{tabular}{|c|c|c|c|c|c|c|c|}
\hline$\beta_{1}$ & Availability & $\begin{array}{c}\text { Profit } \\
* 1.0 \mathrm{e}+004\end{array}$ & MTTF & $\alpha_{1}$ & Availability & $\begin{array}{c}\text { Profit } \\
* 1.0 \mathrm{e}+004\end{array}$ & MTTF \\
\hline 0 & 0.7241 & 7.1379 & 11.2500 & 0 & 0 & -0.2000 & 8.7111 \\
\hline 0.0714 & 0.7056 & 6.9196 & 11.0154 & 0.0714 & 0.2854 & 2.6327 & 9.1805 \\
\hline 0.1429 & 0.6608 & 6.4435 & 10.0376 & 0.1429 & 0.4572 & 4.3597 & 9.5689 \\
\hline 0.2143 & 0.6052 & 5.8679 & 8.6729 & 0.2143 & 0.5536 & 5,3387 & 9.8780 \\
\hline 0.2857 & 0.5492 & 5.2943 & 7.3537 & 0.2857 & 0.6086 & 5.9030 & 10.1203 \\
\hline 0.3571 & 0.4976 & 4.7695 & 6.2445 & 0.3571 & 0.6418 & 6.2456 & 10.3101 \\
\hline 0.4286 & 0.4520 & 4.3076 & 5.3559 & 0.4286 & 0.6628 & 6.4654 & 10.4595 \\
\hline 0.5000 & 0.4124 & 3.9077 & 4.6512 & 0.5000 & 0.6769 & 6.6134 & 10.5781 \\
\hline 0.5714 & 0.3782 & 3.5632 & 4.0890 & 0.5714 & 0.6868 & 6.7173 & 10.6733 \\
\hline 0.6429 & 0.3486 & 3.2659 & 3.6354 & 0.6429 & 0.6939 & 6.7929 & 10.7505 \\
\hline 0.7143 & 0.3229 & 3.0085 & 3.2644 & 0.7143 & 0.6992 & 6.8495 & 10.8138 \\
\hline 0.7857 & 0.3006 & 2.7842 & 2.9570 & 0.7857 & 0.7032 & 6.8930 & 10.8662 \\
\hline 0.8571 & 0.2809 & 2.5878 & 2.6991 & 0.8571 & 0.7063 & 6.9270 & 10.9099 \\
\hline 0.9286 & 0.2636 & 2.4146 & 2.4802 & 0.9286 & 0.7088 & 6.9543 & 10.9468 \\
\hline 1.0000 & 0.2482 & 2.2609 & 2.2924 & 1.0000 & 0.7108 & 6.9763 & 10.9781 \\
\hline
\end{tabular}

Table 4.Variation of availability, profitand MTTF with $\alpha_{0}$ and $\beta_{0}$

\begin{tabular}{|c|c|c|c|c|c|c|c|}
\hline$\beta_{0}$ & Availability & $\begin{array}{c}\text { Profit } \\
* 1.0 \mathrm{e}+004\end{array}$ & MTTF & $\alpha_{0}$ & Availability & $\begin{array}{c}\text { Profit } \\
* 1.0 \mathrm{e}+004\end{array}$ & MTTF \\
\hline 0 & 0.9494 & 9.4304 & 155.0000 & 0 & 0 & -0.1500 & 7.3209 \\
\hline 0.0714 & 0.8824 & 8,7107 & 38.8944 & 0.0714 & 0.2838 & 2.6759 & 8.1412 \\
\hline 0.1429 & 0.7723 & 7.5843 & 16,3659 & 0.1429 & 0.4703 & 4.5422 & 8.9525 \\
\hline 0.2143 & 0.6710 & 6.5597 & 9.8243 & 0.2143 & 0.5933 & 5.7772 & 9.7548 \\
\hline 0.2857 & 0.5873 & 5.7162 & 6.9014 & 0.2857 & 0.6766 & 6.6161 & 10.5484 \\
\hline 0.3571 & 0.5194 & 5.0346 & 5.2816 & 0.3571 & 0.7347 & 7.2040 & 11.3334 \\
\hline 0.4286 & 0.4643 & 3.3816 & 4.2629 & 0.4286 & 0.7766 & 7.6286 & 12.1100 \\
\hline 0.5000 & 0.4190 & 4.0279 & 3.5668 & 0.5000 & 0.8076 & 7.9439 & 12.8781 \\
\hline 0.5714 & 0.3813 & 3.6510 & 3.0626 & 0.5714 & 0.8311 & 8.1836 & 13.6381 \\
\hline 0.6429 & 0.3496 & 3.3339 & 2.6814 & 0.6429 & 0.8493 & 8.3898 & 14.3900 \\
\hline 0.7143 & 0.3226 & 3.0639 & 2.3834 & 0.7143 & 0.8637 & 8.5171 & 15.1340 \\
\hline 0.7857 & 0.2994 & 2.8317 & 2.1443 & 0.7857 & 0.8752 & 8.6355 & 15.8701 \\
\hline 0.8571 & 0.2792 & 2.6300 & 1.9483 & 0.8571 & 0.8845 & 8.7322 & 16.5985 \\
\hline 0.9286 & 0.2615 & 2.4533 & 1.7849 & 0.9286 & 0.8922 & 8.8120 & 17.3194 \\
\hline 1.0000 & 0.2458 & 2.2974 & 1.6465 & 1.0000 & 0.8987 & 8.8787 & 18.0327 \\
\hline
\end{tabular}

Table 5. Variation of availability, profit and MTTF with respect to $\alpha_{0}$ for different values of $\beta_{0}$

\begin{tabular}{|c|c|c|c|c|c|c|c|c|c|}
\hline \multirow{3}{*}{$\alpha_{0}$} & \multicolumn{3}{|c|}{$A_{T}(\infty)$} & \multicolumn{3}{|c|}{$P_{F}(\infty)$} & \multicolumn{3}{|c|}{ MTTF } \\
\hline & \multirow[b]{2}{*}{$\beta_{0}=0.1$} & \multirow[b]{2}{*}{$\beta_{0}=0.5$} & \multirow[b]{2}{*}{$\beta_{0}=0.9$} & $\beta_{0}=0.1$ & $\beta_{0}=0.5$ & $\beta_{0}=0.9$ & \multirow[b]{2}{*}{$\beta_{0}=0.1$} & \multirow[b]{2}{*}{$\beta_{0}=0.5$} & \multirow[b]{2}{*}{$\beta_{0}=0.9$} \\
\hline & & & & $* 10^{4}$ & $* 10^{4}$ & $* 10^{3}$ & & & \\
\hline 0 & 0 & 0 & 0 & -0.0150 & -0.0150 & -0.1500 & 14.1457 & 2.9827 & 1.6635 \\
\hline 0.1111 & 0.6042 & 0.1899 & 0.1113 & 0.8928 & 0.2696 & 1.5165 & 18.6661 & 3.1995 & 1.7315 \\
\hline 0.2222 & 0.7843 & 0.3369 & 0.2082 & 1.1654 & 0.4903 & 2.9704 & 22.9054 & 3.4158 & 1.7994 \\
\hline
\end{tabular}




\begin{tabular}{|l|l|l|l|l|l|l|l|l|l|}
\hline 0.3333 & 0.8545 & 0.4498 & 0.2922 & 1.2723 & 0.6600 & 4.2306 & 26.8890 & 3.6314 & 1.8673 \\
\hline 0.4444 & 0.8881 & 0.5367 & 0.3647 & 1.3240 & 0.7909 & 5.3197 & 30.6394 & 3.8465 & 1.9351 \\
\hline 0.5556 & 0.9067 & 0.6042 & 0.4272 & 1.3526 & 0.8928 & 6.2605 & 34.1765 & 4.0610 & 2.0028 \\
\hline 0.6667 & 0.9180 & 0.6573 & 0.4813 & 1.3701 & 0.9730 & 7.0741 & 37.5179 & 4.2749 & 2.0706 \\
\hline 0.7778 & 0.9253 & 0.6996 & 0.5281 & 1.3816 & 1.0370 & 7.7795 & 40.6795 & 4.4882 & 2.1382 \\
\hline 0.8889 & 0.9304 & 0.7337 & 0.5688 & 1.3895 & 1.0886 & 8.3928 & 43.6754 & 4.7009 & 2.2058 \\
\hline 1.0000 & 0.9340 & 0.7614 & 0.6042 & 1.3952 & 1.1307 & 8.9279 & 46.5183 & 4.9131 & 2.2734 \\
\hline
\end{tabular}

Table 6. Variation of availability, profit and MTTF with respect to $\beta_{0}$ for different values of $\alpha_{0}$

\begin{tabular}{|c|c|c|c|c|c|c|c|c|c|}
\hline \multirow{2}{*}{$\beta_{0}$} & \multicolumn{3}{|c|}{$A_{T}(\infty)$} & \multicolumn{3}{c|}{$P_{F}(\infty)$} & \multicolumn{3}{c|}{ MTTF } \\
\cline { 2 - 7 } & $\alpha_{0}=0.1$ & $\alpha_{0}=0.5$ & \multirow{2}{*}{$\alpha_{0}=0.9$} & $\alpha_{0}=0.1$ & $\alpha_{0}=0.5$ & $\alpha_{0}=0.9$ & \multirow{2}{*}{$\alpha_{0}=0.1$} & $\alpha_{0}=0.5$ & \multirow{2}{*}{$\alpha_{0}=0.9$} \\
\cline { 5 - 10 } & & & & $P_{F} * 10^{4}$ & $P_{F} * 10^{4}$ & $P_{F} * 10^{4}$ & & & \\
\hline 0 & 0.9494 & 0.9494 & 0.9494 & 1.4209 & 1.4209 & 1.4209 & 155.0000 & 155.0000 & 155.0000 \\
\hline 0.1111 & 0.5405 & 0.8893 & 0.9270 & 0.7966 & 1.3258 & 1.3842 & 16.2065 & 28.2793 & 38.4200 \\
\hline 0.2222 & 0.3401 & 0.7869 & 0.8786 & 0.4951 & 1.1693 & 1.3093 & 7.5491 & 11.1872 & 14.6504 \\
\hline 0.3333 & 0.2458 & 0.6079 & 0.8215 & 0.3535 & 1.0223 & 1.2221 & 4.8796 & 6.5778 & 8.2382 \\
\hline 0.4444 & 0.1920 & 0.5405 & 0.7642 & 0.2727 & 0.8984 & 1.1349 & 3.5970 & 4.5727 & 5.5362 \\
\hline 0.5556 & 0.1574 & 0.4850 & 0.7102 & 0.2208 & 0.7966 & 1.0531 & 2.8458 & 3.4774 & 4.1041 \\
\hline 0.6667 & 0.1333 & 0.4391 & 0.6608 & 0.1846 & 0.7131 & 0,9783 & 2.3531 & 2.7948 & 3.2341 \\
\hline 0.7778 & 0.1156 & 0.4006 & 0.6163 & 0.1581 & 0.6439 & 0.9110 & 2.0054 & 2.3313 & 2.6561 \\
\hline 0.8889 & 0.1020 & 0.3680 & 0.5763 & 0.1377 & 0.5860 & 0.8506 & 1.7469 & 1.9973 & 2.2469 \\
\hline 1.0000 & 0.0913 & 0.3680 & 0.5405 & 0.1217 & 0.5370 & 0.7966 & 1.5473 & 1.7456 & 1.9435 \\
\hline
\end{tabular}

Table 7. Variation of availability, profit and MTTF with respect to $\alpha_{1}$ for different values of $\beta_{1}$

\begin{tabular}{|c|c|c|c|c|c|c|c|c|c|}
\hline \multirow{3}{*}{$\alpha_{1}$} & \multicolumn{3}{|c|}{$A_{T}(\infty)$} & \multicolumn{3}{|c|}{$P_{F}(\infty)$} & \multicolumn{3}{|c|}{ MTTF } \\
\hline & \multirow{2}{*}{$\beta_{1}=0.1$} & \multirow{2}{*}{$\beta_{1}=0.5$} & \multirow{2}{*}{$\beta_{1}=0.9$} & $\beta_{1}=0.1$ & $\beta_{1}=0.5$ & $\beta_{1}=0.9$ & \multirow{2}{*}{$\beta_{1}=0.1$} & \multirow{2}{*}{$\beta_{1}=0.5$} & \multirow{2}{*}{$\beta_{1}=0.9$} \\
\hline & & & & $P_{F} * 10^{4}$ & $P_{F} * 10^{4}$ & $P_{F} * 10^{3}$ & & & \\
\hline 0 & 0 & 0 & 0 & -0.0100 & -0.1000 & -0.1000 & 8.7111 & 3.4003 & 2.0638 \\
\hline 0.1111 & 0.3926 & 0.1030 & 0.0591 & 0.5742 & 1.4261 & 0.7747 & 9.4066 & 3.6112 & 2.1471 \\
\hline 0.2222 & 0.5613 & 0.1926 & 0.1136 & 0.8274 & 2.7571 & 1.5830 & 9.9080 & 3.8350 & 2.2349 \\
\hline 0.3333 & 0.6324 & 0.2702 & 0.1641 & 0.9349 & 3.9136 & 2.3333 & 10.2519 & 4.0686 & 2.3270 \\
\hline 0.4444 & 0.6665 & 0.3366 & 0.2109 & 0.9866 & 4.9044 & 3.0289 & 10.4882 & 4.3088 & 2.4231 \\
\hline 0.5556 & 0.6849 & 0.3926 & 0.2540 & 1.0146 & 5.7424 & 3.6713 & 10.6539 & 4.5529 & 2.528 \\
\hline 0.6667 & 0.6958 & 0.4396 & 0.2936 & 1.0313 & 6.4451 & 4.2618 & 10.7730 & 4.7986 & 2.6258 \\
\hline 0.7778 & 0.7028 & 0.4787 & 0.3298 & 1.0421 & 7.0319 & 4.8021 & 10.8608 & 5.0436 & 2.7318 \\
\hline 0.8889 & 0.7075 & 0.5113 & 0.3627 & 1.0493 & 7.5215 & 5.2947 & 10.9271 & 5.2862 & 2.8405 \\
\hline 1.0000 & 0.7108 & 0.5385 & 0.3926 & 1.0545 & 7.9308 & 5.7424 & 10.9781 & 5.5247 & 2.9517 \\
\hline
\end{tabular}

Table 8. Variation of availability, profit and MTTF with respect to $\beta_{1}$ for different values of $\alpha_{1}$

\begin{tabular}{|c|c|c|c|c|c|c|c|c|c|}
\hline \multirow{2}{*}{$\beta_{1}$} & \multicolumn{3}{|c|}{$A_{T}(\infty)$} & \multicolumn{3}{c|}{$P_{F}(\infty)$} & \multicolumn{3}{c|}{ MTTF } \\
\cline { 2 - 7 } & $\alpha_{1}=0.1$ & $\alpha_{1}=0.5$ & $\alpha_{1}=0.9$ & $\alpha_{1}=0.1$ & $\alpha_{1}=0.5$ & $\alpha_{1}=0.9$ & \multirow{2}{*}{$\alpha_{1}=0.1$} & $\alpha_{1}=0.5$ & $\alpha_{1}=0.9$ \\
\cline { 5 - 10 } & & & $P_{F} * 10^{4}$ & $P_{F} * 10^{3}$ & $P_{F} * 10^{3}$ & & & 11.2500 & 11.2500 \\
\hline 0 & 0.7241 & 0.7241 & 0.7241 & 1.0759 & 1.0759 & 1.0759 & 11.2500 & 11.259 \\
\hline 0.1111 & 0.3397 & 0.6677 & 0.7043 & 0.4950 & 0.9884 & 1.0444 & 9.0313 & 10.3983 & 10.8348 \\
\hline
\end{tabular}




\begin{tabular}{|l|l|l|l|l|l|l|l|l|l|}
\hline 0.2222 & 0.1947 & 0.5638 & 0.6568 & 0.2788 & 0.8313 & 0.9719 & 6.4848 & 8.1911 & 9.2809 \\
\hline 0.3333 & 0.1358 & 0.4695 & 0.5989 & 0.1913 & 0.6895 & 0.8841 & 4.9354 & 6.2731 & 7.4395 \\
\hline 0.4444 & 0.1042 & 0.3958 & 0.5412 & 0.1444 & 0.5790 & 0.7972 & 3.9529 & 4.9334 & 5.9189 \\
\hline 0.5556 & 0.0846 & 0.3397 & 0.4887 & 0.1152 & 0.4950 & 0.7183 & 3.2850 & 4.0104 & 4.7903 \\
\hline 0.6667 & 0.0712 & 0.2964 & 0.4427 & 0.0954 & 0.4304 & 0.6493 & 2.8045 & 3.3548 & 3.9658 \\
\hline 0.7778 & 0.0614 & 0.2625 & 0.4031 & 0.0809 & 0.3798 & 0.5898 & 2.4436 & 2.8719 & 3.3548 \\
\hline 0.8889 & 0.0540 & 0.2353 & 0.3690 & 0.0700 & 0.3393 & 0.5388 & 2.1632 & 2.5044 & 2.8916 \\
\hline 1.0000 & 0.0482 & 0.2131 & 0.3390 & 0.0614 & 0.3062 & 0.4950 & 1.9393 & 2.2167 & 2.5320 \\
\hline
\end{tabular}

